\title{
Population Change in Canada
}

\author{
by Don Kerr and Roderic Beaujot \\ 3rd edn, Don Mills, ON: Oxford University Press 2016 \\ ISBN 978-0-19-900262-7 \\ Softcover $\$ 64.95,448 \mathrm{pp}$.
}

\author{
Reviewed by Anthony C. Masi \\ Desautels Faculty of Management, McGill University
}

The authors designed this monograph primarily as a supplementary text for courses dealing with population studies or as complementary reading in social sciences or public policy offerings that would benefit from content on Canada's demography. It is well-suited for both purposes. Indeed, many individual chapters would make excellent required reading in specialist courses on a variety of topics.

Following a now-characteristic formula of OUP textbooks, the Kerr and Beaujot volume has a decidedly pedagogical style: each chapter starts with an "at a glance" box that in addition to providing highlights of what is to be presented also serves implicitly to outline specific learning objectives. Then the authors provide carefully researched and clearly written arguments for the topic at hand, and conclude by posing questions for critical thought, providing annotated recommended readings and pointing to related websites. Throughout the book, words and phrases placed in italics are (usually) defined in the glossary. The bibliography included at the end of the book is a masterful compilation of materials that have either been cited directly or have influenced the development of the substantive topics covered.

After two brief introductory chapters, one on the study of population change and the other on Canada's population prior to the 20th century, the volume is divided into three parts: population processes (chapters on mortality, fertility, immigration); growth, distribution, and aging (chapters on population distribution, internal migration and the regions, the implications of changing growth patterns, and population aging); and the consequences of population change (chapters on families and households, sociocultural and socioeconomic composition, the demography of Canada's Aboriginal peoples, and population and the environment). Following a summary concluding chapter, there are four appendices (the life table; rates and standardization; the 2014 world population data sheet; and population estimates and demographic accounts), the aforementioned glossary, references, and a comprehensive subject index.

This volume is more than a simple update of the second edition (Beaujot and Kerr 2004), which appeared over a decade ago. It contains new materials on Canada's pre-Confederation demography, the demographic history of First Nations peoples, and a detailed consideration of the interplay between population growth and the environment that places Canada's story in global context. Another feature is that topics are consistently framed in relation to population change: processes undergo variations, leading to structures and compositions that deviate from previous states, leading to processes with new values and changed context.

Faithful to the intent of the first edition of this book (Beaujot 1991), which carried the subtitle "challenges of policy adaptation," this third edition also explores appropriate policy responses on the part of governments when forced to "consider the impact of demographic change on fundamental aspects of Canadian society" (p. xi). Indeed, sensitivity to socioeconomic and political matters is what renders the Kerr-Beaujot volume a potentially interesting choice for courses across the spectrum of the social sciences. Any courses dealing with First 
Nations issues would be well advised to assign Chapter 11, "The Demography of the Aboriginal Population of Canada," and pages 16 to 23 of Chapter 2 (pre-contact native population issues) as required readings.

Focusing attention on processes, structures, and consequences enables Kerr and Beaujot to treat each demographic topic in a discursive, non-technical manner, while being able to refer interested readers to the appendices, supplementary materials, or related websites for required details. Further, within the well-designed and clearly written chapters, the authors employ another standard OUP textbook device to address interesting, difficult, or controversial subjects: the sidebar box. Here are some examples: avoidable mortality (Box 3.2, p. 48-52), attitudes toward having children (Box 4.2, p. 84-86), the economic adjustment of immigrants (Box 5.6, p. 129-130), immigration and labour force growth (Box 7.1, p. 180-81), university credential, over-qualification, and the Canadian labour force (Box 10.2 p. 268-69), and the number of status Indians (Box 11.1, p. 282-83). In addition, they also use this tool to touch upon vital theoretical and/or methodological issues without losing the reader in mechanical and technical details, as in: the cohort as a concept in studying social change (Box 8.1, p. 195-97), immigration as a solution to population aging (Box 8.2, p. 198-200), and defining "family" (Box 9.1, p. 227).

Chapter 7, "Changing Growth Patterns and Their Implications," although not citing it directly, and Chapter 2, "The Population of Canada before the Twentieth Century," which does cite it, recall some of the themes presented in Beaujot and McQuillan's 1982 book, Growth and Dualism: The Demographic Development of Canadian Society.

Chapter 12, "Population and the Environment," is another example of a section of this book that can be employed standalone as required reading in courses dealing with (the human impact on) the health of the planet Earth. Here again, Kerr and Beaujot use the sidebar to get at topics not usually covered in introductory courses in population studies, e.g., "Box 12.1: Taking a Closer Look at Canada's Record on GHG Emissions" (p. 307-10) and "Box 12.2: How Large is Our Ecological Footprint?" (pp. 312-15).

The treatment of some of topics will not be to the liking of everyone, but each topic is covered in a way that allows for discussion, debate, and dissent. In addition, the volume could have been shortened by eliminating the appendices and simply referring readers to other print or digital sources. Greater attention might have been given to the design and presentation of some tables, with an eye to eliminating clutter and redundancy. These, however, are small quibbles that do not detract from the overall quality of the effort and output.

This volume also marks an impressive milestone for Professor Roderic Beaujot—an important book dealing with Canadian demography in every one of the last four decades.

\section{References}

Beaujot, R. 1991. Population Change in Canada: The Challenges of Policy Adaptation. Toronto: Oxford University Press.

Beaujot, R., and D. Kerr. 2004. Population Change in Canada. 2nd edn. Toronto: Oxford University Press.

Beaujot, R., and K. McQuillan. 1982. Growth and Dualism: The Demographic Development of Canadian Society. Toronto: Gage. 